This item was submitted to Loughborough's Research Repository by the author.

Items in Figshare are protected by copyright, with all rights reserved, unless otherwise indicated.

\title{
Learning alliances for integrated and sustainable innovations in urban water management
}

\section{PLEASE CITE THE PUBLISHED VERSION}

\section{PUBLISHER}

(C) WEDC, Loughborough University

\section{VERSION}

VoR (Version of Record)

\section{PUBLISHER STATEMENT}

This work is made available according to the conditions of the Creative Commons Attribution-NonCommercialNoDerivatives 4.0 International (CC BY-NC-ND 4.0) licence. Full details of this licence are available at: https://creativecommons.org/licenses/by-nc-nd/4.0/

\section{LICENCE}

CC BY-NC-ND 4.0

\section{REPOSITORY RECORD}

Verhagen, Joep, John Butterworth, and Mike Morris. 2019. "Learning Alliances for Integrated and Sustainable Innovations in Urban Water Management”. figshare. https://hdl.handle.net/2134/30309. 
33rd WEDC International Conference, Accra, Ghana, 2008

\author{
ACCESS TO SANITATION AND SAFE WATER: \\ GLOBAL PARTNERSHIPS AND LOCAL ACTIONS
}

\title{
Learning alliances for integrated and sustainable innovations in urban water management
}

\author{
Joep Verhagen, John Butterworth, The Netherlands \& Mike Morris, UK
}

\begin{abstract}
In a rapidly changing and ever more complex world, 'wicked problems' that traditional narrowly-focused research struggles to grapple with, are more and more common including. in the water sector. Here, numerous good practices derived through traditional research have showed a remarkable resistance towards scaling up. This paper discusses the Learning Alliance approach and its application to try and overcome the twin challenges of solving complex problems and scaling-up innovations in urban water management. Learning Alliances are interlinked multi-stakeholder platforms formed at appropriate levels. Critically, the purpose of a Learning Alliance is to do things differently, rather than to do different things, in order to have more impact on policy and practice. The paper summarises initial experiences and lessons learned applying this approach in three urban water management projects.
\end{abstract}

\section{Background: Why do we need new research partnerships in urban water management?}

Cities around the world face a range of dynamic pressures including rapid population growth and urban sprawl, industrialization and de-industrialisation, and climate change. The ecological 'footprints' of cities are generally growing, rapidly in some developing countries, through increasing exploitation of available resources while urban centres produce massive streams of waste (solid, gaseous, liquid) contaminating soils, air and water. It is expected that by 2030 approximately 5.1 billion people (out of a total global population of 8.1 billion people) will live in urban areas ${ }^{1}$. Most of this urban growth will take place in less developed countries.

Conventional urban water management meanwhile, both in the North and the South, is struggling to manage ever scarcer water resources, deliver water and sanitation services and dispose of wastewater and mitigate the impacts of extreme weather events that cause droughts and urban floods, without adversely impacting the quality of life of urban populations and the downstream environment. Put bluntly, urban water management faces extraordinary and complex - or 'wicked' - problems where solutions to problems in one part of the system may create new problems elsewhere for others (Rittel and Webber, 1973, 1984, Pacanowsky, 1995, both quoted by Lach, Rayner and Ingram). The conventional management paradigms developed in 19 th century Europe are poorly suited to this challenge.

Researchers have the potential to contribute to tackling complex problems such as urban water management through contributions that are context-specific, demand-led, and integrated, and through outcomes that are communicated well to all stakeholders. This paper discusses an approach - the 'Learning Alliance Approach' - that is intended to promote such research and has been tested in several recent and on-going programmes.

\section{Urban water management as a "wicked" problem}

We have described urban water management as a wicked problem. Why? Wicked problems "have incomplete, contradictory, and changing requirements; and solutions to them are often difficult to recognize as such because of complex interdependencies." (Rittel and Webber 1973). They have the following characteristics:

- There is no definite formulation of a wicked problem and every problem is essentially unique and dynamic. Solutions cannot be simply replicated but need to be reinvestigated and adapted for each specific situation.

- There is no stopping rule and therefore one can always improve the solution. 
- Solutions are often inventive or creative and require a 'group effort'.

- Perfect solutions do not exist - they are not true or false but rather more or less suitable for a specific problem.

- The view on problems and their solutions is subjective and context dependent. Different stakeholders hold different viewpoints and preferences and this makes it problematic to judge the quality of the solution.

- Wicked problems can never be completely solved. They can only be improved.

Rapid urbanisation, increasing water scarcities, growing waste streams, competition for space combined with a strong fragmentation of the urban water sector make urban water management and especially the integration thereof a typical 'wicked problem'.

Tackling wicked problems needs an approach that moves beyond 'traditional science'. Silver bullets do not exist. The boundaries between scientists and practitioners and outsiders and insiders need to be softened, researchers need to take up the role of capacity builders and a multi-disciplinary approach needs to be taken. More of the same type of research that has partly led to current fragmented urban water cycles is unlikely to lead to the solution of wicked problems, but rather to isolated improvements at best, not without the possibility of unintended and detrimental outcomes elsewhere in the system.

Recent approaches to improving the impact of research and development take a different approach to stimulating innovation and achieving an impact at scale. They place greater emphasis on the rapidly changing socio-economic, political and environmental contexts, and on the importance of a diversity of key actors and organisations in effecting an innovatory environment and facilitating scaling-up. Scaling up in this context is understood to refer to long-term sustainability (scaling up in time) and $100 \%$ coverage (scaling up in space). Accordingly, the focus has switched from producing knowledge through research towards the acquisition and application of knowledge by concerned stakeholders. In other words, the knowledge incorporated by local actors is being seen as the main development impact of research.

The Learning Alliance approach is derived from work on innovation systems. This work explores the relationships between science and technology and the economic performance of industrial countries. Innovation in this context is essentially associated with the commercialisation of technologies (i.e. ideas, hardware, practices) with a focus on adapting existing knowledge rather than creating new knowledge as such (Arnold \& Bell, 2001).

\section{Learning alliances}

The Learning Alliance approach is an attempt to find an answer to two interlinked phenomena that we argue are present in urban water management: wicked problems and a general failure to scale up innovations. The approach is premised on the idea that the key challenge to impact is not in devising new technologies but in bringing about appropriate institutional change within the relevant innovation system.

\section{Learning alliances}

A Learning Alliance is a series of interlinked stakeholder platforms from a given innovation system that seeks to realise widespread impact through the up-scaling of an innovatory approach. Through working on the agreed underlying problems, and contesting and evolving together potential solutions (i.e. action research mode), it is anticipated that mechanisms for addressing institutional constraints and enhancing institutional learning will be generated.

Some key principles underlying the approach are:

- Learning Alliances should be formed around real, potentially wicked problems, and an initial group of stakeholders committed to change. Learning Alliance members will share a common desire to address an underlying problem, for example, to improve urban water management. They will also share or develop common approaches - visions, strategies and tools - on how this can be achieved. Not all stakeholders will (actively) participate from the very beginning but might decide to join later. Each platform will group together a range of stakeholders who capture diversity and bring together complementary skills and experiences.

- The more representative the alliance is, the better it will capture the institutional complexities that constitute the realities of the system. Representation needs to be ensured horizontally - that is stakeholders working for instance the city level - and vertically - that is stakeholders working at community, city, and national level for example (see Figure 1). Good stakeholder analysis is critical to ensure representation. 
- Emphasis is switched from researchers devising new technologies - doing different things - to improving how the multiple stakeholders in the innovation system work - doing things differently - and will lead to interventions having greater impact;

- Innovations that are generated locally, taking all the relevant stakeholders into account, are more likely to lead to appropriate, integrated and sustainable solutions, to promote flexible and adaptive working practices, and to foster and strengthen the development capacity of local organisations and communities;

- New understanding of knowledge and learning should be promoted, and the emergence of learning organizations. Whereas information can be generated and disseminated, knowledge is viewed as a complex, transformative process, arising less from any accumulated stock of information, and more from intra- and inter-organizational processes in which experimentation - action research - and communication feature strongly.

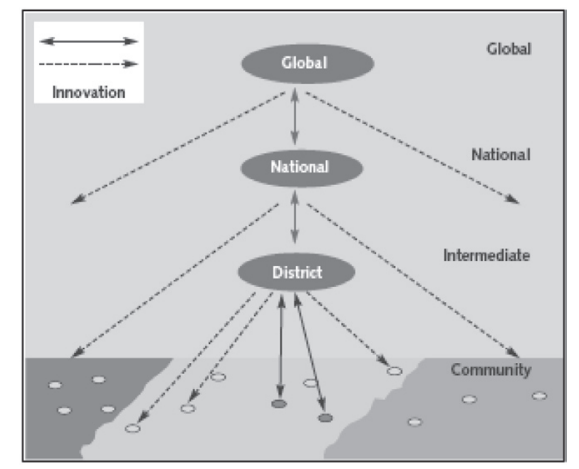

Figure 1. Interlinked stakeholder platforms

Source: Smits et al. 2007

\section{Learning Alliance experiences in urban water management}

The learning alliance approach has its origins outside the water sector (see Smits et al 2007 for a wider discussion) but has been recently applied in a number of urban water management innovation and development projects. Here we review some of these recent experiences.

\section{Euro-Med participatory water resources scenarios (EMPOWERS) ${ }^{2}$}

EMPOWERS, through generous allocation of funding from the European Union and committed project management, fully adopted the learning alliance approach and the concept of multiple stakeholder platforms for dialogue and change was built into the programme from the outset. EMPOWERS, completed in 2007, involved a regional partnership of fifteen organizations allied to improve long-term access to water by local communities in Jordan, Egypt, and Palestine. The focus of the programme was on developing scalable approaches for community-managed water supply mainly in small towns and rural areas.

Within the programme, ample resources and time were allocated for learning, establishment and facilitation of Learning Alliances and process documentation. Full-time facilitators and documentation specialists were employed to serve the Learning Alliance in each of the countries. Moreover, EMPOWERS invested in developing the capacity of the local facilitators (and provided back up of more senior facilitators on a parttime basis). Initial investment and the strong orientation on process eventually paid off. A tedious start up phase was overcome, and EMPOWERS managed to make a strong impact at all levels of the Jordanian water sector for example. The EMPOWERS programme captured many of its valuable insights into how Learning Alliances need to be facilitated, their strengths, and limitations in a toolkit for local water governance ${ }^{3}$.

In one of the documentaries that was produced for EMPOWERS, high-ranking Jordan government officials narrate that it was their first time to actually have prolonged and meaningful discussions with representatives from local communities. Water supplies were improved in a number of villages on the basis of plans developed by the communities and local authorities. 


\section{Wastewater agriculture and sanitation for poverty alleviation (WASPA) ${ }^{4}$}

The WASPA programme seeks to develop approaches to enhance the safe reuse of wastewater by urban farmers in Bangladesh and Sri Lanka, thus improving both urban sanitation and strengthening the livelihoods of poor urban farmers. The complexities (politically, socially, economically, environmentally) of the urban fringe in these countries make this a clear example of a wicked problem, which the learning alliance approach aims to address.

The Learning Alliances that have been set up as part of the WASPA project are however poorly resourced. For instance, it was not even possible to hire a part time Learning Alliance facilitator and support from international partners was limited to two annual visits. Consequently, Learning Alliances have been set up at the city level only and they function poorly as there is only limited buy-in from important stakeholders such as city corporations. Given the limited resources to start up and facilitate and support Learning Alliance processes, the project period of three years has proven to be too short to make a real impact.

\section{Sustainable water management improves tomorrow's cities' health (SWITCH) ${ }^{5}$}

SWITCH is a large-scale research project comprising of 34 partners, with research and demonstration activities in 9 demo-cities across the world and a budget of $€ 15$ million. The project is expected to produce demand-led research on Integrated Urban Water Management (IUWM) that eventually leads to a paradigm shift in urban water management in these cities. It focuses on closing the cycle of urban water systems through promoting the treating and reuse of wastes, demand management, decentralized approaches to service delivery and related innovations. The Learning Alliance approach has been identified as the vehicle to try and drive this paradigm shift.

The project is in the process of overcoming a number of crucial problems.

i. Research activities in cities were originally identified without involvement of city learning alliances since these didn't exist when the research issues were framed at the proposal and design stage of the project. This has seriously hampered the demand-led character of the research and its integration.

ii. Secondly, Learning Alliances were not funded at the outset as it was expected that cities would pay for them. This ignored the fact that the change process towards IUWM was being initiated (at least partly) by an external party and was not fully demand-driven. Limited resources have hampered the setting up of the city Learning Alliances and the ability to recruit senior level facilitators.

iii. Finally, within the SWITCH consortium there has been considerable resistance against the change towards demand-led and integrated research especially when this introduces uncertainty about how financial resources will be allocated. Critically, management structures for the programme were not related to the implications of a learning alliance approach which require a matrix type of management structure representing the interests of research users (e.g. cities) and research providers (e.g. Universities and scientific institutes).

\section{Lessons learned}

Although the programmes and projects described have their own peculiarities and specificities a number of general lessons have been learned to date:

- Allocate realistic funding for learning alliance processes especially when change processes are initiated by outsiders. Building partnerships can be costly and while the benefits may eventually outweigh the costs, the investments needed are too easily underestimated and under budgeted in our experience. Learning Alliances need a champion who drives the process and at least one full-time facilitator who brings local stakeholders together. These roles cannot be played by the same person. Experience has shown that a project following the Learning Alliance process needs to allocate funding for (a) at least a full time facilitator per project area e.g. city; (b) detailed process documentation; (c) a series of stakeholder workshops in particular during the start up phase of the project; and (d) bi-monthly support visits by support agencies. Moreover, there is a need for flexibility to allocate funding for action-research identified by the Learning Alliance members.

- Identify and involve stakeholders based on a thorough stakeholder analysis. This should especially involve those stakeholder groups that are normally excluding from decision-making processes but who are highly affected by decisions. Special measures might need to be taken to ensure the involvement of these groups.

- Flexible and realistic time planning setting up a Learning Alliance, developing a commonly shared vision, agreeing upon objectives and establishing effective communication between Learning Alliance 
members takes time and progress will vary between projects. Initial progress will be slow and often frustrating and it can take up to a year before a Learning Alliance is fully functional. However, experience has shown that this initial investment is necessary to tackle wicked problems and or produce scalable solutions.

- Communicate results effectively. At its heart, a learning alliance is a platform for experiential learning, communicating the findings from that learning and receiving effective feedback. Effective communication that is focused on learning for change is a necessity. Such communication might necessitate different and unusual forms to meet different stakeholders needs (e.g. interim publications such as working papers and draft policy briefs for discussion, video diaries, newsletters, interactive websites and exposure visits etc).

- Focus on learning for change. Learning alliances are intended to be forums for learning, learning that is linked to action research, pilots or demonstrations with results that are intended to be implemented or scaled-up by some of the participants. However, learning needs to be planned for and encouraged, otherwise the alliance will remain a platform for information sharing and little more.

- Invest in facilitation and documentation. Effective facilitation of meetings and other activities, and good documentation, provides a powerful incentive for participants to be involved in learning alliance processes as does effective communication between events (e.g. through websites, quarterly reports, newsletters etc). Facilitation and documentation requires specific skills and experience that are mostly found with mid-level and senior professions. It is however rare to find the facilitation, influencing and documentation skills needed in a single person and consideration should be given to splitting documentation, process research (e.g. stakeholder analysis) and documentation roles.

- Create incentives for involvement. It is possible to be creative to build the interests of stakeholders and empower learning alliances. Alliances should be given as many decision-making roles as possible, for example in selection of research partners or locations as well as the issues. Using such platforms to identify MSc and PhD students for scholarships can build local capacities rather than sending in outsiders. Small flexible budgets for the learning alliance to commission small studies and other activities can also be highly effective.

- Avoid separation of science and process. Everyone should be, and feel, part of an innovative learning alliance. Scientists who treat learning alliances as dissemination platforms fail to grasp the possibilities and needs. Without innovative content from new science, which often will need to be presented in novel ways, even the best planned process will stall as stakeholders lose interest.

- Identify and build upon existing structures. Whenever possible learning alliances need to be built on existing stakeholder-platforms or network arrangements.

- Conflict is inherent to change. Those benefiting from the status quo are usually happy to continue in their position of power and are unlikely to voluntarily concede to rule changes by others. Resistance to change is often the norm and has to be understood and tackled.

- Don't underestimate time needed and resistance to change. There are also many good reasons why things are done in the way they are done. More holistic approaches will rarely come easily or fast just by sitting people around a table and sharing information. Real change in the positions of individuals, and crucially the organisations represented by those individuals, is slow and hampered by existing organisational cultures in which powerful individuals are reluctant to see the status quo, and their particular grasp of power and resources, diminished. Project management structures are crucial to balancing the interests of research providers and users and should be carefully designed.

- Monitor the outcomes of Learning Alliance processes. Monitoring is needed to learn and justify costs, but is challenging and remains a relatively undeveloped area.

\section{Conclusions}

By their very definition, wicked problems related to urban water management do not have simple solutions. It would be naïve to expect any kind of partnership approach, like learning alliances, to address all the problems of traditional research in this field but we believe the examples and lessons learned to date can improve the effectiveness of that science. However, we would like to end with a word of caution. Even well funded learning alliances with a high level of commitment will struggle to overcome vested powers that are often well entrenched. All too often partnership type processes are promised by researchers in project proposals, but frequently these fail to materialise and live up to expectations. The experiences to date highlight that the cost and level of commitment and effort needed should be considered carefully before adopting a learning alliance approach. 


\section{References}

Arnold E. and Bell M. (2001), Some New Ideas About Research for Development, in Danish Ministry of Foreign Affairs: Partnership at the Leading Edge: A Danish Vision for Knowledge, Research and Development (April 2001). Down load from http://www.um.dk/NR/rdonlyres/7CD8C2BC-9E5B-4920929C-D7AA978FEEB7/0/CMI_New_Ideas_R_for_D.pdf

Lach, D., Rayner, S. and Ingram, $\bar{H}$. 2005. Taming the waters: strategies to domesticate the wicked problems of water resource management. Int. J. Water, Vol. 3, No. 1, pp.1-17.

Pacanowsky, M. 1995. Team tools for wicked problems, Organizational Dynamics, Vol 23, No 3, pp 3652; as quoted by Lach, D., Rayner, S. and Ingram, H. 2005. Taming the waters: strategies to domesticate the wicked problems of water resource management, Int. J. Water, Vol. 3, No. 1, pp.1-17.

Moriarty, P., Fonseca, C., Smits, S., Schouten, T., Butterworth, J., \& Green, C. 2006. Learning Alliances for scaling up innovation and realising integrated urban water management. [online] Available at www.switchurbanwater.eu/page/1346

Rittel, H. and Webber, M. 1973. Dilemmas in a general theory of planning, Policy Sciences, Vol. 4, No. 2 , pp.155-169; as quoted by Lach, D., Rayner, S. and Ingram, H. 2005. Taming the waters: strategies to domesticate the wicked problems of water resource management, Int. J. Water, Vol. 3, No. 1, pp.1-17.

Rittel, H. and Webber, M. 1984. 'Planning problems are wicked problems', in Cross, N. (Ed.): Developments in Design Methodology, Wiley, NY.

Smits, S. Moriarty. P. and Sijbesma. C. (eds) 2007. Learning Alliances Scaling up innovations in water, sanitation and hygiene. Technical Paper Series 47. IRC International Water and Sanitation Centre Delft, the Netherlands [online] Available at www.irc.nl/page/35887

\section{Referenced websites}

Euro-Med Participatory Water Resources Scenarios (EMPOWERS) - www.empowers.info Wastewater Agriculture and Sanitation for Poverty Alleviation (WASPA) - www.iwmi.cgiar.org/WASPA/ Sustainable Water management Improves Tomorrow's Cities' Health (SWITCH) - www. switchurbanwater.eu

\section{Acknowledgements}

This paper is adapted from a working paper on learning alliances by John Butterworth and Mike Morris that can be downloaded at www.switchurbanwater.eu/page/1340 Further information can also be found at www.switchurbanwater.eu/learningalliances. The EMPOWERS, WASPA and SWITCH projects are all supported by various grants from the European Commission.

\section{Endnotes}

1 Source: United Nations Population Fund (UNFPA) http://www.unfpa.org/swp/1999/chapter2d.htm accessed on February 5, 2008.

2 www.empowers.info

3 www.empowers.info/page/2850

${ }^{4}$ www.iwmi.cgiar.org/WASPA/

5 www.switchurbanwater.eu/learningalliances

\section{Keywords}

multi-stakeholder platforms, wicked problems, change management, innovation, urban water management, learning alliances 


\section{Contact details}

Joep Verhagen

IRC International Water and Sanitation Centre

Delft, The Netherlands

Tel: +31 152192942

Email: verhagen@irc.nl

www: www.irc.nl

John Butterworth

IRC International Water and Sanitation Centre

Delft, The Netherlands

Tel: + 31152192949

Email: butterworth@irc.nl

www: www.irc.nl

Mike Morris

World Wildlife Fund UK

Godalming, UK

Tel: +44 1483412560

Email: mmorris@wwf.org.uk

www: www.wwf.org.uk 